\title{
Influences of the Microstructure on the Drift velocity of Electromigrating Aluminum through Molybdenum disilicide Thin films
}

\author{
Julia Baldauf ${ }^{1}$, Martin Schädel ${ }^{1}$ \\ ${ }^{1}$ CiS Forschungsinstitut für Mikrosensorik GmbH, Konrad-Zuse-Straße 14, 99099 Erfurt, Germany, \\ jbaldauf@cismst.de
}

\begin{abstract}
Summary:
A difference of the drift velocity of aluminum could be observed for polycrystalline thin film conductor lines made of molybdenum disilicide with different grain sizes in the scanning electron microscope.
\end{abstract}

Keywords: electromigration, thin film

\section{Background and Motivation}

Because of its high melting point molybdenum disilicide $\left(\mathrm{MoSi}_{2}\right)$ [1] is often used in MEMS hotplates [2,3], which can be applied as IR light source in NDIR gas measurement systems. Electromigration and diffusion within the $\mathrm{MoSi}_{2}$ or the materials of the electric contact pads through the resistive heating layer are reasons for device failures and limits for long term stability and life time [3]. Electromigration properties of $\mathrm{MoSi}_{2}$ thin films are hardly investigated in the literature. Some findings described in $[4,5,6]$ show the electromigration of aluminum of the electrical contact pads through $\mathrm{MoSi}_{2}$ thin films, without giving detailed information about the drift velocity of the aluminum. Here we address the issue of the drift velocity of aluminum through molybdenum disilicide thin films. The knowledge of the drift velocity allows to make predictions of the life time of devices using molybdenum disilicide layers.

\section{Experiments}

A $70 \mathrm{~nm}$ thick layer of silicon oxide was grown on n-type silicon wafers were used as a substrate. A $500 \mathrm{~nm}$ thick layer of silicon nitride was deposited via low pressure chemical vapour deposition. A $100 \mathrm{~nm}$ thick layer of molybdenum disilicide was magnetron sputtered from a stoichiometric target without use of substrate heating at a pressure of $5 \times 10^{-3} \mathrm{mbar}$.

The molybdenum silicide layer was annealed under different conditions shown in Table 1.
Tab. 1: Annealing conditions

\begin{tabular}{|c|c|}
\hline Sample & Atmosphere: temperature (time) \\
\hline A & $\begin{array}{c}100 \% \mathrm{~N}_{2}: 500^{\circ} \mathrm{C}(60 \mathrm{~min})+900^{\circ} \mathrm{C} \\
(120 \mathrm{~min})\end{array}$ \\
\hline B & $\begin{array}{c}100 \% \mathrm{H}_{2}: 500^{\circ} \mathrm{C}(60 \mathrm{~min})+800^{\circ} \mathrm{C} \\
(60 \mathrm{~min})+900^{\circ} \mathrm{C}(120 \mathrm{~min})\end{array}$ \\
\hline C & $\begin{array}{c}100 \% \mathrm{~N} 2: 500^{\circ} \mathrm{C}(60 \mathrm{~min})+800^{\circ} \mathrm{C} \\
(60 \mathrm{~min})+900^{\circ} \mathrm{C}(120 \mathrm{~min})\end{array}$ \\
\hline D & $100 \% \mathrm{H}_{2}: 500^{\circ} \mathrm{C}(60 \mathrm{~min})$ \\
\hline
\end{tabular}

The resulting crystal structure was analyzed via electron backscatter diffraction (EBSD). For samples $A, B$, and $C$ the annealing caused the amorphous molybdenum silicide layer to transform into a polycrystalline layer of grains of the tetragonal crystal phase of molybdenum disilicide with different grain sizes. The average grain size of sample A ( $0.343 \mu \mathrm{m}$ diameter) was smaller and the distribution of the grain size was narrower than the grain sizes of samples $B$ and $C$. With samples $B$ and $C$ having similar grain sizes and distributions. Sample D stayed amorphous. After the annealing step the molybdenum silicide layer was structured and electrical contacts made of aluminum silicon alloy were deposited. Schematics of the test structures are shown in Figure 1. 

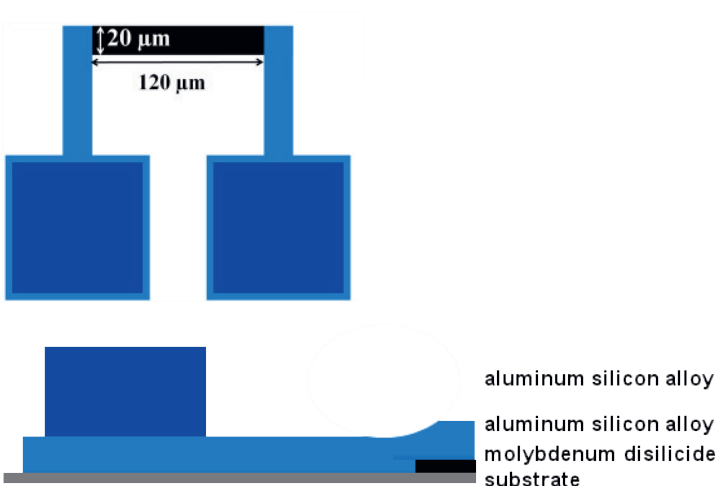

Fig. 1 Schematic of the test structures, top view and cross section.

Test structures have been stressed with current densities from $1.7 \times 10^{6} \mathrm{~A} / \mathrm{cm}^{2}$ up to $3.0 \times 10^{6} \mathrm{~A} / \mathrm{cm}^{2}$. While applying a constant current the cathode end of the molybdenum disilicide stripe was monitored via scanning electron microscope to investigate the time needed for the formation of hillocks. Because of the structure geometry the aluminum forming the hillock can only be aluminum which was formerly present at the anode and has electromigrated through the molybdenum silicide test stripe. Figure 2 shows a cathode before and after the growth of a hillock.

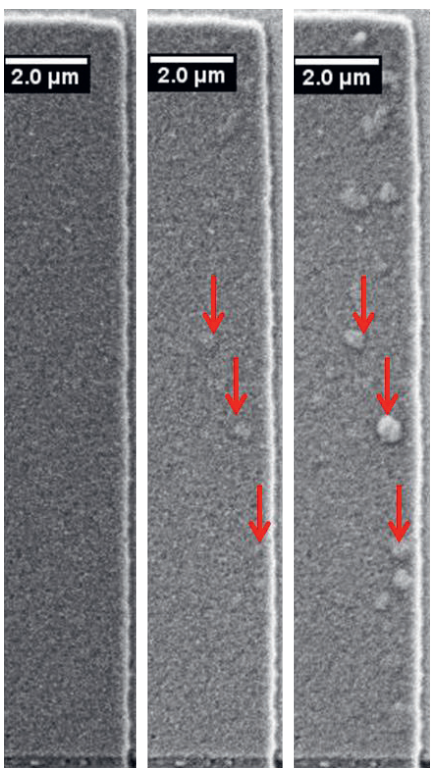

Fig. 2 Aluminum alloy cathode end before (left) and after (middle, and right) formation of hillocks.

From this observation an average drift velocity could be calculated. The drift velocities of the aluminum through the test structure ranged from $1.04 \times 10^{-7} \mathrm{~m} / \mathrm{s}$ to $8.57 \times 10^{-6} \mathrm{~m} / \mathrm{s}$ depending on the current density and the microstructure of the thin film (see Figure 3).

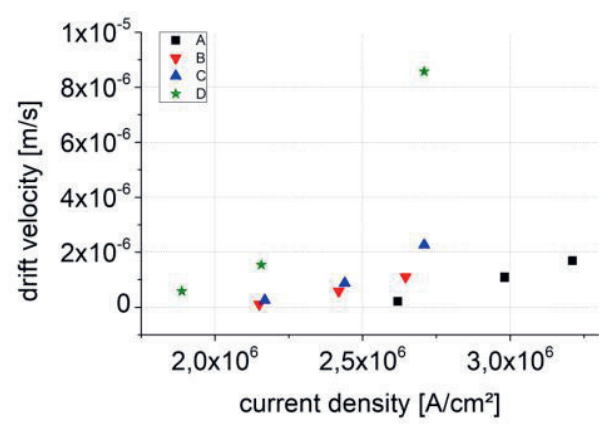

Fig. 3 Drift velocity of aluminum in the test structures depending on the current density.

$B$ and $C$ have similar grain structures and behaviors of drift velocity. Sample A showed lower drift velocities. The electromigration of aluminum being strongly dependent on the grain boundaries has also been reported in [6]. With annealing it is possible to tune the grain structure and reduce the electromigration of aluminum through the molybdenum disilicide layer.

\section{References}

[1] A. B. Gokhale, G. J. Abbaschian, R.W. Olesinski and G. J. Abbaschian, In Binary Alloy Phase Diagrams, vol. 2, T. B. Massalski (editor) (ASM, Ohio, 1986) pp. 1631, 2062.

[2] G. Beensh-Marchwicka, E. Prociów, and T. Berlicki, Thin film heater and thermopile built up using some silicides under thermal test, 2006 29th International Spring Seminar on Electronics Technology, St. Marienthal, 2006, pp. 475-478; doi: 10.1109/ISSE.2006.365152.

[3] Y. Ito, M. Sato, K. Wakisaka, and S. Yoshikado, Improvement of heating characteristics of molybdenum silicide thin film electrical heaters, Electrical Engineering in Japan 168 (2007),11-19; DOI: 10.1002/eej.20806

[4] A. Zehe, A. Ramirez, Electromigration of Aluminium through Quasi Bamboo- Like Grain Blocked Silicide Interconnects, Cryst. Res. Technol. 35 (2000), 557-562; doi: 10.1002/15214079(200005)35:5<557::AIDCRAT557>3.0.CO;2-M

[5] A. Zehe, The stress-induced escape of migrating aluminium from silicide interconnects, Semicond. Sci. Technol. 16 (2001), 817-821; DOI: 10.1088/0268-1242/16/301

[6] A. Zehe, A. Ramirez, A. Corona, Migrationforced metal extrusion from passivated molybdenum disilicide interconnects, Materials Letters 57 (2002), 55-58; doi:10.1016/S0167$577 \times(02) 00698-5$

\section{Acknolodgements}

Thanks are due to A. Graff, and D. Zwanzig, Fraunhofer IMW, Halle, for EBSD measurements.

Parts of this research were funded by the german "Bundesministerium für Wirtschaft und Energie" (BMWi) within the ongoing project "EMIR“ (Innokom, 49MF190017). 